\title{
Research on the Effects of Task Repetition in TBLT and Its Recycling Use in EFL Learners' Oral Production
}

\author{
Shuzhen Fang 1,2, * \\ ${ }^{1}$ School of Foreign Languages, Guangdong Innovative Technical College, Dongguan City, 523960, Guangdong \\ Province, P.R. China. \\ ${ }^{2}$ School of Education, University of Leeds, West Yorkshire, United Kingdom \\ *Corresponding author. Email: $382284893 @ q q . c o m$
}

\begin{abstract}
This paper reports on a study that was primarily aimed at exploring the benefits of using TR for two times in English teaching for non-English major freshmen in a specific higher vocational college. It investigates the effect of applying an intermediate TR in TBLT procedure, and a second TR in one week's interval. Recordings were made of 3 students of markedly different English level performing the task in both 2 times of TR. Follow-up interviews were conducted on the teaching teacher and these 3 students. Results revealed that obvious improvement were achieved in oral production regardless of the students' English level in the first TR. However, when applied in the second time, no further gain was spotted in general, indicating that effect of TR may have been related to the teacher's scaffolds and the students' being notified of TR purpose in advance. The obtained results also show implications for teachers and practitioners in EFL context.
\end{abstract}

Keywords: task repetition, fluency, accuracy, complexity, EFL context, non-English major

\section{RESEARCH BACKGROUND AND SIGNIFICANCE}

Developing students' oral skills is a key goal for English classes in many parts of world. In recent decades, research about teaching speaking, especially English language, has been boosted dramatically. Repetition as a task-based teaching process has drawn much attention from researchers in the last two decades [2] [4]. Task repetition (henceforth TR) refers to 'repetition of the same or slightly altered task- whether the whole tasks, or parts of a task' [6]. 'Task' involves a pedagogical activity focusing on meaning, where learners/users need to refer to their linguistic resources in order to achieve communicative purpose [6]. For example, in a task of describing a picture, the students' priority would be the content of this picture, and have little time to think about the suitable words or grammatical structure to fill in the content. In the process of TR, there are generally two performances. The first performance of the task is regarded as preparation for the second performance; in other words, the preparation of familiarity with forms and content
[5]. Then by doing the same (or a slightly altered) task for a second time at intervals of, for example, one or two weeks [6], learners' attention which was given in the first time might be freed up to access more linguistic resources (i.e., vocabulary and grammatical structures) in their speech production.

As stated above, the effect and purpose of TR is theoretically straightforward, and practically accessible by teachers. Nevertheless, is it effective in improving learners' oral production in real class teaching? Is it possibly more effective to use it for a second time? On students' side, their perception and interpretation of TR play an important part since students' belief will affect the learning process.

In response to these, this study attempted to answer the following research questions:

1 Does the first TR bring accurate, fluent and complex language use in oral production?

2 Does the second TR bring more improvement in oral production?

3 How do students perceive the first and second TR respectively? 


\section{LITERATURE REVIEW}

\subsection{Task and TR}

Since the early 1980s, tasks have been extensively used in teaching and assessing language as a practical instrument. The task starts from meaning and content, ends with production, and the process of using the correct forms of words and grammatical structure becomes motivation to achieve meaningful production, instead of boring drills. TR, a task-based implementation variable, has also been the research focus over the past two decades. [2][4]

\subsection{Theoretical effects of TR}

To explain the relevance of TR to oral performance improvement, it is useful to refer to Levelt's (1989) [12] speech production model. According to Levelt's (ibid.) model, speech production is achieved through three overlapping stages:

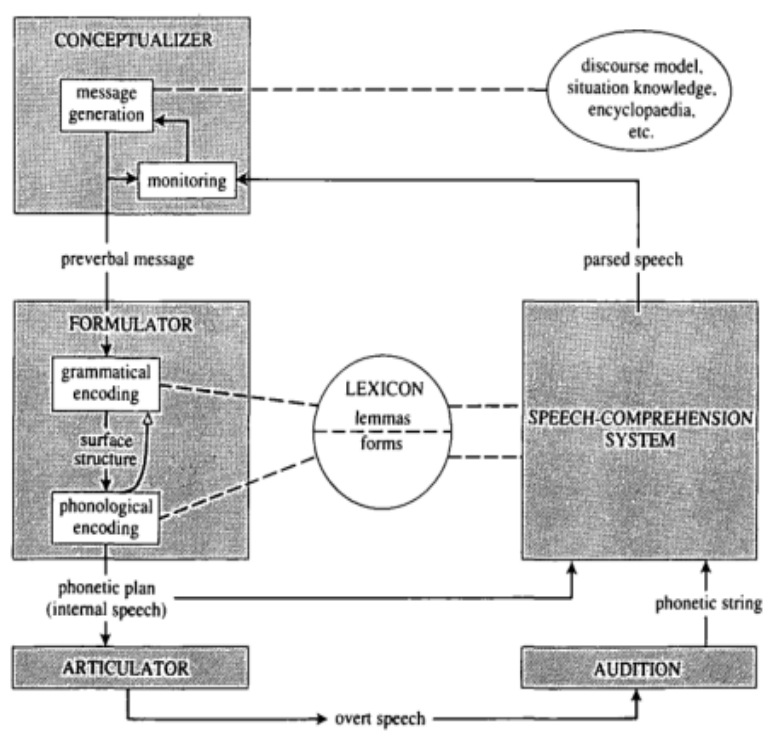

Figure 1 Levelt's speech production model (Levelt 1989: Fig. 1.1)

"Task repetition involves relating the new performance to information kept in the long-term memory (LTM) store.[4]. In the conceptualization process, memory of task content is stored for the initial task performance; a repetition of the same (or slightly alternated) task is likely to enable speakers to refer to the working memory for this task content including the details of input materials. To this extent, TR can be considered as a process of schematic development in memory store [6]. Furthermore, the familiarity of the task is more likely to help the process of conceptualization go faster and the capacity to the other two stages is released for the possibilities of better performance in the second time.

In the perspective of formulation, two impacts of TR can be identified: the processing of formulation and the product.[6]

As outlined/summarized above, the effect of TR on conceptualization process can help free up more capacity to attend to formulation process. To begin with, this extra capacity can reactivate the bond of conceptual content and lexico-grammatical forms; secondly, it can speed up the lexico-grammatical selection processing. With this time and capacity as gains, the performance as product is targeted to be meaningful in concept, lexically appropriate, and grammatically accurate.

In the perspective of articulation, the first performance of a task is less effective [6], since the knowledge and skills of articulation is much dependent on the long previous

learning history instead of the immediately previous (i.e., the encounter of task).

\subsection{Empirical Study of TR}

An early attempt to study the effect of TR was carried out by Bygate (1996) [3]. In his quantitative study, 11 participants were shown a silent cartoon video extract and then were asked to retell the story. With 10 weeks intervals without advanced notification, the participants were asked to repeat the same task: watching the same cartoon and retell the story. Next, these two performances were compared, and it was found that remarkable improvement in the quality of talk occurred in this process of TR, both in terms of grammatical complexity and lexical fluency. He continued to discuss that these findings supported the hypothesis that in the first performance, the leaner prioritize the planning of task content, and therefore lack sufficient time to search for linguistic resources. While in the second time, with the familiarity and comfort with the task content, the participants can attend to their linguistic performance. Similarly, Ahmadian and Tavkoli (2011) [2] reported that TR has positive effect on complexity and fluency in L2 speech production. Nevertheless, these researches have one common limitation that the task is wholly about narration of a silent video and based on monologue, which lack actual communicative environment and purpose.

In 2000, Lynch and Maclean [13] conducted a communication-oriented study based on TR in an ESP (English for Specific Purposes) teaching context. The study was carried out using 'poster carousel' as a task. All the 14 participants were divided into 2 groups, with one host standing in front of each 7 posters, and six visitors clockwise moving one by one in each group. The host was assigned to answer different questions 
about the post from each visitor for about 3 minutes. Tape recording and follow- up questionnaires were analyzed, with the result showing that this kind of TR positively affected the accuracy and fluency of L2 oral production. Lynch and Maclean's [13] (2000) study demonstrated at least three significances. Firstly, the repetition of task in this study was not simply duplicated as defined in the literature.[2] [3[4]]; instead, the content of both questions and responses are different since the posters and visitors who interacted with the hosts are different. It's more real-life communication. Secondly, the activity in this study was carried out in a conversational style instead of the previous monologue one, which echoed Levelt's (1989) [12] insight: "The most primordial and universal setting for speech is conversational, free interaction between two or more interlocutors." (p. 29) Thirdly was the design of 6 different visitors in each group. Bygate (1996) [3] already in his study proposed the effect of repeating the task with different partners: 'different people will do tasks in different ways and a variety of partners could provide different learning opportunities $^{\text {[3] }}$. With different partners as variables in the study, it could help record and reflect the actual impact of TR, and thus more helpful as reference for other researchers when they consider their own context.

As is noted above, TR involves time, and the repetition is usually conducted at intervals, for example, within 1 week [8], 1 week [1] [2], or longer. Repeating the task immediately was also carried out by several studies [9][11]. These studies showed that immediate TR was beneficial to the learners' speech processing ability. One most relevant study was from Hawkes (2011) [9]. The study involved the second-year private junior high school students in Japan, investigating the immediate effect of repetition by putting this repetition within a task cycle in TBLT teaching. Data were analyzed both qualitatively and quantitatively, and indicated that initial attention on meaning was replaced by attention on form in the repeat performance. In order to make this teaching process more intelligible, a figure is illustrated as follows, and is adopted and slightly modified in this article.

The first two items of left column in figure 2 were based on Willis and Willis's (2007, cited in Hawkes, 2011[9], p330) description, where main task is the final part in a standard version of TBLT. But in Hawkes' (2011) [9] study, he attached 'form focus' and 'repeat performance' in the sequence of teaching for his investigation. 'Form focus' could be regarded as feedback from the teacher and awareness of form noticing; while 'repeat performance' was expected as a TR, where learners showed more attempts to use L2 with better accuracy and confidence. Hawkes' (2011) [9] study provides an inspiring framework in this article, in the way that TR can be applied in the TBLT teaching cycle; together with teacher's intervention, the immediate output in the second time are expected to be reinforced.

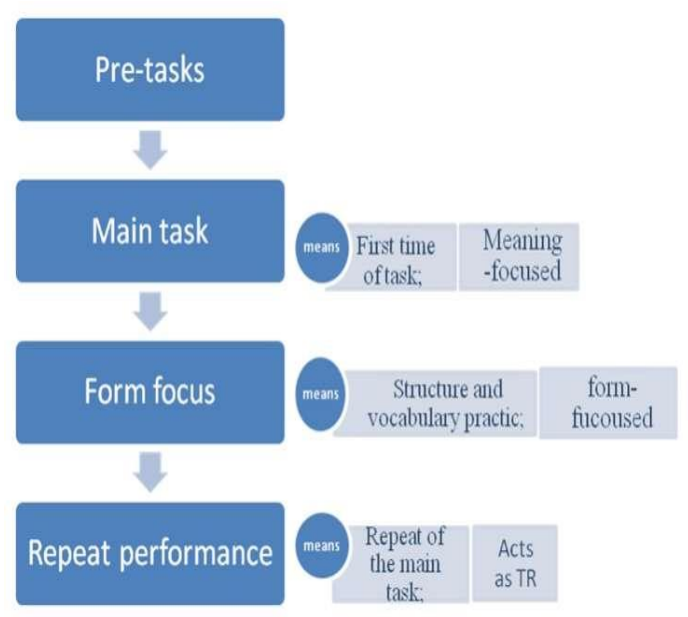

Figure 2 The task sequence in Hawkes' (2011) study

\subsection{Possible Limitation of TR}

Plough and Gass (1993), cited in Gass et al.'s (1999) [8]. study, indicated that 'learners can easily become somewhat disinterested in the tasks given to them when those tasks have been carried out repeatedly'. (p.572). On the contrary, in Ahmadian and Tavkoli's (2011) [2] study, even though the teachers assumed that TR was boring and disinteresting to students, a majority of students maintained that TR was not boring. In this article, the possible limitation of TR will be explored in the interview as well, since students' attitude towards TR will bring effect on the teacher's teaching and learners' learning.

\section{RESEARCH DESIGN}

\subsection{Research Sample and Object}

This study was conducted in a provincial-governed higher vocational college in Dongguan, with nonEnglish major freshmen as the research sample, whose English levels were various, but mostly preliminary. This investigation was carried out in the second semester of their academic year, where students had had one semester's accumulation of linguistic and communicative aspects.

\subsection{Research Methods and Questions}

In order to explore the research questions, a qualitative study involving both teacher and students was employed, including observation during the classes and audio-recorded interviews to the teaching teacher and 3 students after the classes. Both teacher and students were invited to conduct the interview, since both of their perspectives of class will exert influences 
on the classroom learning and performance [10]. From teacher's interview, the empirical evidence of effects of TR can be found, hopefully providing further insight of teaching for teachers. Interviews from students have more contributions. Firstly, students' perspectives plus teacher's data will help make the research results more objective. Secondly, possible limitation of TR can be explored from some specific questions concerning students' feelings about TR. Finally, during the interview, students' voices are heard, and this respect will boost students' learning autonomy and motivation to some extent in later learning.

\subsection{Research Procedure and Data Collection}

TR, which was carried out both immediately and at intervals, has its merits. Therefore, in the design of this study, TR was applied twice. To be more specific, the first time of TR was within the task cycle in TBLT; the second time of TR was carried out in another class after one week, which was operationally applied in most of the previous studies [1][2][8]. Hawkes' (2011) [9] design was adopted and slightly modified in this study. The sequence of teaching is shown in figure 2 .

One teacher and 35 students in one class participated in the two rounds of TR processing. In these two rounds, full observation was conducted. More specifically, 3 students' oral performances were audio-recorded. After the 2 rounds of TR, these 3 students and teaching teacher were invited for a semiconstructed interview and audio-recorded. To ensure the representativeness of sample, 3 students were chosen according to their different speaking proficiency level, namely, basic, intermediate, and advanced level. Informed consent forms were signed by both teacher and 3 students. For reasons of anonymity, the teacher is called $\mathrm{T}$, and students are called $\mathrm{S} 1$ (advanced level), S2 (intermediate level) and S3 (basic level) hereinafter in this study.

As is shown in figure 3 the TBLT activity was about ordering food in Macdonald's. After the main task (focused on meaning), teacher's form focus was explicitly involved, for example, teacher presented the target language item, the language points, etc; students practiced the items, got help from teacher and at least got familiar with these language items; then repeat performance (acted as first TR) was processed. This TR process was expected to be the same way as 'main task', and the same partner should be guaranteed. After one week, students were operated the TR for a second time. The task was still ordering food; but this time, there were some modifications. Firstly, the task was slightly different: food was ordered in KFC; secondly, their partners were different. No notification of repeating this task was notified beforehand.
As soon as the second TR was completed, participants (both 1 teacher and 3 students) were invited to take part in one-on-one semi-structured audiorecorded interviews. (Sample questions can be referred to in Appendix 1, and parts of the questions are adapted from Ahmadian, Mansouri, and Ghominejad's study (2017)[1] Each interview took between 10 and 15 minutes, during which learners were asked questions about how they perceived their oral performance in the first and second TR respectively, their improvement of oral performance in the first and second TR respectively, and what aspects of emotion they were affected (both negatively and positively) by the first and second TR respectively. On teacher's part, questions were asked about what aspect of L2 performance and learning improvement from learners they had noticed in the first and second TR respectively, and the feeling of doing doing TR twice on students.

Interviews were carried out in Mandarin Chinese to exclude the variable of language-related misunderstanding and vagueness. All interviews were transcribed into English and one professor was consulted with for the translation reliability. Next, the data was categorized by applying content analysis method.

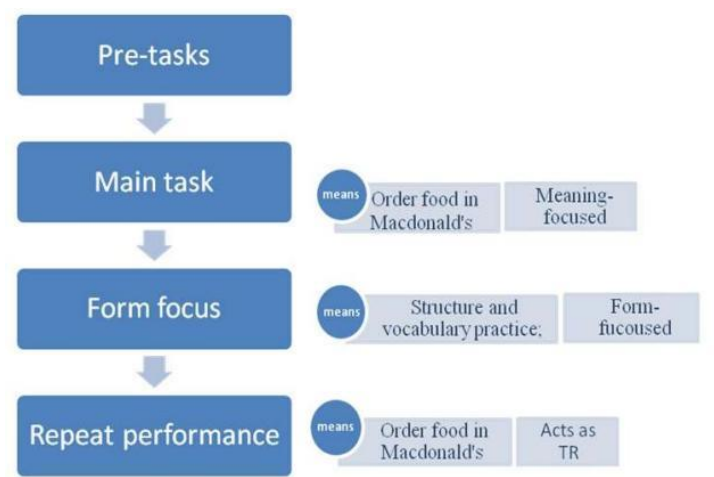

Figure 3 Application of Hawkes' (2011) design as the First TR

\section{RESEARCH FINDINGS AND DISCUSSION}

The findings are aimed to answering my three research questions as follows:

1 Does the first TR bring accurate, fluent and complex language use in oral performance?

2 Is the second TR effective as the first one?

3 How do students perceive the first and second TR respectively? 


\subsection{The Effect of 'repeat Performance' as the First Immediate TR}

\subsubsection{Attention from Meaning to Form}

Above all, both the teacher and students reached consensus that TR was effective in overall performance. Students were generally positive about this TR. S1 commented that 'the repetition can combine what I already knew and what the teacher just taught in a more accurate way' and $\mathbf{S 2}$ said that 'it was a good way to practice what the teacher have just taught us.' $\mathbf{S 3}$ noted that:

When doing the 'main task', I spent a lot of time to think about what to say and how to say in sentences; but in the 'repeat performance', I could just repeat the same content, but having a better structure, and even more content.

In this TBLT activity, the goal was to place an order in a restaurant. In the 'main task', the students tended to focus their attention of the content, because task was meaning-focused [6]. Therefore, in the 'form focus' stage, three target language forms were highlighted to help students: the pronunciation of food names; sentence structure in ordering food, and asking questions from customer's need.

In the 'repeat performance', there is evidence that students paid more attention to the target forms.

The comments and examples in Table 1 are highly consistent with Levelt's (op.cit.) speech production model and Bygate's (1996) [3] idea. According to Bygate, the $1^{\text {st }}$ encounter of task takes up the students' much time and attention on the conceptualization stage (i.e., what to say); and on $2^{\text {nd }}$ occasion, since the students are aware of the content in the task, they can pay more attention to the formulation and articulation stages, and better production can be achieved.

\subsubsection{Fluency, Accuracy and Complexity}

The concurrent agreement in both students' and teacher's response is the improvement in fluency. On the students' side, comments were more or less the same, "I felt smoother"(S2), "I could speak a bit more quickly"(S3), and "it was like reciting"(S1); the teacher stated that "Good job! They really put great efforts in practicing the language forms presented in form-focus stage".
In terms of accuracy, the response was slightly different. All three students claimed that they paid more attention to the pronunciation, words and/or grammatical structures to various extents, but their performance still showed some accuracy concerns, despite of their obvious improvement. For example, S1 said that "in main task I was not sure if 'to go' was right to express packing the food but not eating in the restaurant; but in the repeat performance, I was pretty confident, so in this TR, I could use the phrase more accurate." $\mathbf{S 3}$ explained that "I could pronounce some words correctly in the repeat performance from teacher's help from form-focus stage, such as 'order', but some words, like, 'Mexican Twister', I'm still not sure about its pronunciation."

In the aspect of complexity, the improvement was oblivious, but the term 'complexity' did not lie in the long sentences with difficult structure, but in the sense of more turn-takings. To be more detailed, S1 from 4 turns to 7 turns, $\mathbf{S 2}$ from 2 turns to 7 turns, and $\mathbf{S 3}$ from 2 turns to 6 turns respectively. To make it more comprehensible, the dialogues were presented below for comparison (S2's partner is called S4):

It can be thus concluded from Table 2 that the 'repeat performance' as the first TR can boost the fluency, accuracy, and complexity to different extent, and was in alignment with the previous empirical studies illustrated in $2.2^{[3][8]}$.

\subsection{The Effect of Second TR}

The effect of the second TR is a bit interwoven From the teacher's comment, students definitely talked more and better than that in 'main task', both in terms of attention to forms, fluency and accuracy. However, they talked less than that in the 'repeat performance'. It can be interpreted that TR is indeed functioned in improving students' oral performance, but if the TR is carried out again, the effect is not as obvious as that in the first TR. For example, S1 from 7 turns to 6 turns, $\mathbf{S 2}$ from 7 turns to 5 turns, and $\mathbf{S 3}$ from 6 turns to 3 turns respectively. What's more, most of the students seemed to simply copy everything from the first TR, even the same food. It was justified to say that students were too involved in the task itself, paying too much attention on the correctness of language use, instead of using the language for real communicative purpose. 
Table 1. Attention to form in the 'main task' and 'repeat performance'

\begin{tabular}{|l|l|l|}
\hline Students & In the 'main task': & In the 'repeat performance': \\
\hline \multirow{3}{*}{ S2 } & What do you need to eat? & What would you like to eat? \\
\cline { 2 - 3 } & Is anything else youneed? & What else would you like? \\
\hline S3 & I want to a Mini Burger. & I'd like a Miri Burger. \\
\hline
\end{tabular}

Table 2. Complexity in the 'main task' and 'repeat performance'

\begin{tabular}{|l|l|l|}
\hline Turn-takings & In the 'main task': & In the 'repeat performance' (lst TR): \\
\hline 1 & $\begin{array}{l}\text { S2: Hello! } \\
\text { S4: I want to Mini Burger. }\end{array}$ & $\begin{array}{l}\text { S2: Can I help you? } \\
\text { S4: Yes. }\end{array}$ \\
\hline 2 & $\begin{array}{l}\text { S2: Is anything else you need? } \\
\text { S4:7 up } \\
\text { S2: OK Wait, please }\end{array}$ & $\begin{array}{l}\text { S2: What would you like to eat? } \\
\text { S4: I'd like a Miri Burger and Cola. }\end{array}$ \\
\hline 3 & & $\begin{array}{l}\text { S2: what do you prefer, Small or Large? } \\
\text { S4: Small. }\end{array}$ \\
\hline 4 & & $\begin{array}{l}\text { S2: What do you prefer, ice or no ice? } \\
\text { S4: Less ice. }\end{array}$ \\
\hline 5 & & $\begin{array}{l}\text { S2: What else would you like? } \\
\text { S4: No, thank you. }\end{array}$ \\
\hline 6 & & $\begin{array}{l}\text { S2: How will you pay, cash or Alipay? } \\
\text { S4: Alipay }\end{array}$ \\
\hline 7 & & $\begin{array}{l}\text { S2: Just a moment, please. } \\
\text { S4: OK }\end{array}$ \\
\hline
\end{tabular}

On the students' side, all of the three students perceived that they had no problem with the content of this task and focused more on the correct forms and fluency. But 2 of them said they forgot some pronunciation of food and certain structures, for example, 'medium', and 'just a moment'. In terms of complexity, since the task is slightly different, there is some food they might not know. S2's strategy is avoidance by using the food taught in the first TR by teachers even though she did not actually want that food. She noted: "It's more secured to use the familiar words that I remember in the talking, because in this way I feel more confident and comfortable"

For S1, who is in relative advanced level, some efforts were made to relate the dialogue with real-life context. He ordered food which was different from the first TR and added more details in the second TR, which in some way indicates that the first TR has helped him internalize the language into real communication:

S1's partner: Do I need to change the snack?

S1: 'No, thanks' (吕 $\left.1^{\text {st }} \mathrm{TR}\right)$

S1: 'No, thanks, but please give me one extra package of ketchup'. (In $\left.2^{\text {nd }} \mathrm{TR}\right)$

From what's been covered above, the second TR tends to have more demerits than its merits. The reasons for this can be integrated with students' attitude towards the second TR.

\subsection{Students' Attitude towards 2 TRs}

In regards to the first $\mathrm{TR}$, all of the three students agreed that the first TR was very helpful in improving the understanding and using the language forms, and thus helpful in improving oral performance as a whole. According to S3, "because the teacher provided us with the correct forms and sufficient practice, I could talk better in the repeat performance (i.e., $1^{\text {st }} \mathrm{TR}$ )". Likewise, S2 said, "I was more confident when performing again"; and S1 also added, "I feel comfortable in performing because I was more familiar with the task."

The attitude towards $2^{\text {nd }} \mathrm{TR}$, however, was quite different from one another. $\mathbf{S 2}$ noted, "not boring at all. The $2^{\text {nd }}$ TR was also helpful, because 'practice makes perfect'." But the other two students were not so positive. S3, said that, "You cannot say it's boring. It's OK for me. It's a task from the teacher, and I have to finish it. That's all." While S1, of the most advanced level, commentated that:

I think it's very boring because we are doing the same thing ('ordering food') for 3 times (in 'main task', $1^{\text {st }} \mathrm{TR}$ and $\left.2^{\text {nd }} \mathrm{TR}\right)$. I am sure I have known enough from the first TR, so the $2^{\text {nd }}$ TR makes no sense.

The students' attitude towards the second TR can partly help explain the reasons of less turn-takings in the $2^{\text {nd }}$ TR illustrated in 4.2. The novelty of the task 
disappeared; boredom and fatigue feeling broke in, therefore, they tended to talk less in the dialogue.

As for the practicality of TR for 2 times, which was in accordance to the students' question as "Which TR is more helpful for your students/you to improve their/your oral performance, the first one or the second one?", the teacher and students provided similar responses. The teacher expressed that 2 TRs were supposed to be helpful, "after all, practice makes perfect". But from teacher's intuition, the students would feel bored in the $2^{\text {nd }} \mathrm{TR}$, "because less is more, and more is less."

Students all agreed that the $1^{\text {st }}$ TR was more helpful since teacher's guidance was involved, they could get practice to get more familiar with the language forms, and they were still interested in the topic. But in the $2^{\text {nd }}$ TR, two out of the three students complained that they were tired of talking so much, and cut the dialogue short. This finding was in line with Plough and Gass's (1993) suggestion which was cited in Gass et al.'s (1999) [8] study.

There are two interesting findings during the interview. The objectives of the $1^{\text {st }} \mathrm{TR}$ was obvious to both the teacher and students from the very beginning, but none of the students were aware of the purpose of the $2^{\text {nd }}$ TR. $\mathbf{S} 2$ confirmed that if the second TR was notified to the students in advance, she would have carried out more productive dialogues since she would had reviewed the language forms accordingly. This provides some implication in the process of teaching: if the purpose of TR is shared with students, students' learning engagement can be activated. This activation echoes Fullan's (2001) [7] comment on students 'as participants in a process of change' (p.104) in 2.2. As Reschly and Christenson [14] pointed out, learning engagement of a task was 'the glue or mediator' (p.3) to link the task, the student, the interlocutors and the teacher.

Another interesting finding was the task selection. S3 with basic level commented that he thought the $1^{\text {st }}$ TR was helpful because the task was a dialogue, and it was interactive and related to real life; but if the task was about independent narration or monologue, he would just give up since it was difficult. This point of view also echoes the rationale in the task design described in 3.1 for this study, that this dialogue task involves authentic communication rather than laboratory setting narration of silent videos. [2][3][4][8]. Implications for task selecting in this teaching context are: tasks are better to be dialogue-based and functionoriented, that is, more applicable to authentic life.

\section{CONCLUSION}

This study sought to find out whether TR is effective in improving students' oral production. There are 2 times of TR involved in this study. The findings show that in the first TR, both the teacher and students found it very helpful in improving fluency, accuracy and complexity. However, in the second TR, students performed a little backward than in the first TR, but better than in the 'main task' stage in TBLT process. It indicates that TR is helpful when they got the teacher's assistance and the awareness of TR purpose was raised; but more than one TR is not necessary or practical. In the aspect of students' attitudes towards the first TR and second TR, again, all students are positive towards the first TR, claiming it brings along confidence and improvement in oral performance; while in the second TR, two out of the three think that it brings boredom and fatigue.

There are some implications for the teaching as well. Firstly, it's important for students' to know the purpose of TR, which is a good way to enable students to devote their engagement to the learning and achieve better performance; secondly, due to basic level students in this teaching context, it's wise to select tasks which are function-oriented and more related to their real life, in which they find more interactive and tended to participate more. Ongoing study of using TR in designs in other teaching activities and investigation of their effect on a larger scale of participants are suggested in the future.

\section{REFERENCES}

[1] Ahmadian, M. J., and Mansouri, S. A. 2017Language learners' and teachers' perceptions of task repetition. ELT Journal, 71(4), pp.467- 477. doi:10.1093/elt/ccx011

[2] Ahmadian, M. J., and Tavakoli, M. 2011. The effects of simultaneous use of careful online planning and task repetition on accuracy, complexity, and fluency in EFL learners' oral production. Language Teaching Research, 15(1), pp.35-59. doi:10.1177/13621688103

[3] Bygate, M. 1996. Effects of task repetition: appraising the developing language of learners. In: Willis and D. Willis.eds. Challenge and Change in Language Teaching. London: Heinemann, pp. 134-46.

[4] Bygate, M. 2001. 'Effects of task repetition on the structure and control of oral language'. In $\mathrm{M}$. Bygate, P. Skehan, and M. Swain. eds. Researching Pedagogic Tasks: Second Language Learning, Teaching and Testing. Harlow: Longman.

[5] Bygate, M. 2006. 'Areas of research that influence L2 speaking instruction'. In: E. Uso'-Juan and A. Mart1 'nez-Flor. eds. Current Trends in the 
Development and Teaching of the Four Skills. Berlin: Mouton de Gruyter.

[6] Bygate, M. and V. Samuda. 2005. 'Integrative planning through the use of task repetition'. In: R.Ellis.ed. Ellis, R., 2009. Task-based language teaching: Sorting out the misunderstandings. International Journal of Applied Linguistics, 19, pp. $221-246$.

[7] Fullan, M. 2001. The new meaning of educational change. 3rd ed. London: New York

[8] Gass, S., Mackey, A., Alvarez-Torres, M. J., and Fernández-García, M. 1999. The effects of task repetition on linguistic output. Language Learning, 49(4), pp.549-581. doi:10.1111/0023-8333.00102

[9] Hawkes, M. 2011. 'Using task repetition to direct learner attention and focus on form'. ELT Journal Advance Access published 12 September 2011; doi:10/1093/elt/ccr059.

[10] Holliday, A, 2013. 'Investing Cluture'. Chapter3, pp25-44, Understanding Intercultural Commnication. Abingdon: Routledge.
[11] Lambert, C., Kormos, J., and Minn, D. 2017. Task repetition and second language speech processing. Studies in Second Language Acquisition, 39(1), pp.167-196. doi:10.1017/S0272263116000085

[12] Levelt, W. J. M. 1989. Speaking. From Intention to Articulation. Cambridge, Mass.: The MIT Press

[13] Lynch, T. and J. Maclean. 2000. 'Exploring the benefits of task repetition and recycling for classroom language learning'. Language Teaching Research 4/3: 221-50.

[14] Reschly, A. and S. Christenson. 2012. 'Jingle, jangle, and conceptual haziness: evolution and future directions in the engagement construct'. In S. Christenson, A. Reschly, and C. Wylie.eds. Handbook of Research on Student Engagement. New York, NY: Springer

[15] Shuzhen, Fang. Research on the Effects of Task Repetition in TBLT and Its Recycling Use in EFL Learners' Oral Production. [D]. West Yorkshire, United Kingdom;University of Leeds, 2019. 